\title{
The classical photoactivated drug 8-methoxypsoralen and related compounds are effective without UV light irradiation against glioma cells
}

\author{
Diêgo Madureira de Oliveira ${ }^{\text {a, b, * }}$, Rute Maria Ferreira Lima ${ }^{c}$, Jorge Clarencio ${ }^{\mathrm{d}, \mathrm{e}}$, \\ Eudes da Silva Velozo ${ }^{\mathrm{f}}$, Ilza Alves de Amorim ${ }^{\mathrm{f}}$, Tales Henrique Andrade da Mota ${ }^{\mathrm{g}}$, \\ Silvia Lima Costa ${ }^{\mathrm{c}}$, Fábio Pittella Silva ${ }^{\mathrm{b}}$, Ramon dos Santos El-Bachá ${ }^{\mathrm{c}}$ \\ a Department of Biological Basis of Health Sciences, Ceilândia Campus, University of Brasilia, Federal District, Brazil \\ ${ }^{\mathrm{b}}$ Laboratory of Molecular Pathology of Cancer, University of Brasilia, Federal District, Brazil \\ ${ }^{c}$ Laboratory of Neurochemistry and Cell Biology, Institute of Health Sciences, Federal University of Bahia, Bahia, Brazil \\ d Gonçalo Moniz Research Center - Fiocruz, Bahia, Brazil \\ e School of Medicine and Public Health of Bahia, Bahia, Brazil \\ ${ }^{\mathrm{f}}$ LAPEMM, Faculty of Pharmacy, Federal University of Bahia, Bahia, Brazil \\ ${ }^{\mathrm{g}}$ School of Pharmacy, Ceilândia Campus, University of Brasilia, Federal District, Brazil
}

\section{A R T I C L E I N F O}

\section{Article history:}

Received 26 February 2016

Received in revised form

16 May 2016

Accepted 7 June 2016

Available online 10 June 2016

Chemical compounds studied in this article: Methoxsalen (PubChem CID: 4114)

Coumarin (PubChem CID: 323 )

Psoralen (PubChem CID: 6199)

7-Methoxycoumarin (PubChem CID: 10748)

Osthole (PubChem CID: 10228)

Coumurrayin (PubChem CID: 176911)

Trioxsalen (PubChem CID: 5585)

Keywords:

Glioma

8-methoxypsoralen

Psoralen

Coumarins

\begin{abstract}
A B S T R A C T
Currently, there is no effective therapy for high grade gliomas. 8-Methoxypsoralen (8-MOP) is a compound used in the treatment of skin diseases combined with UV light irradiation. In this work, rat glioma C6 cells, normal astrocytes and human glioblastoma GL-15 cells comprised an in vitro model to evaluate the antitumor activity of 8-MOP. We found that 8-MOP promoted a time- and concentration-dependent reduction of cell viability in tumor, but not in normal cells. This effect was more evident in log-phase growing culture, indicating antiproliferative activity, which was confirmed by colony formation assay. Long-term effect of 8-MOP at low concentration was also attested. The concentrations used in the tests $(0.02-0.4 \mathrm{mM})$ were lower than plasmatic concentration found in patients. Despite the treatment leads to considerable morphological changes and apoptosis when used at high concentrations, 8-MOP did not promote cell cycle arrest, change in migration pattern neither necrosis. In addition, we evaluated the effect of 8-MOP in MDA-MB-231, CT-26 and SCC-3 cell lines, derived from other kind of primary tumors, and found that CT-26 cells did not respond to 8-MOP treatment, indicating that this compound does not act through a generic mechanism. Coumarin derivatives structurally related to 8-MOP were screened for its antitumor potential and presented different patterns of biological activity, and then it was possible to suggest the relevance of 8-MOP molecular structure for antiproliferative action. Therefore, 8-MOP, a drug with an outstanding record of safety, and related coumarins are good prototypes for development of a new class of anti-glioma drugs.
\end{abstract}

() 2016 Elsevier Ltd. All rights reserved.

\section{Introduction}

Gliomas, tumors of neuroepithelial tissue, are the most common primary brain tumors in adults with an annual incidence of 5.26 per 100,000 population; despite many studies on this theme, the

\footnotetext{
* Corresponding author. Department of Biological Basis of Health Sciences, University of Brasilia, Ceilandia Campus, Federal District, 72220-900, Brazil.

E-mail addresses: dmadureira@unb.br, diego.madureira@pq.cnpq.br (D.M. de Oliveira).
}

impact of technological advances on clinical outcome has not been satisfactory (Omuro and DeAngelis, 2013; de Oliveira et al., 2009). The drug resistance is an important cause of poor clinical outcomes (Garrido et al., 2014), and then new therapeutic approaches, treatments and drugs are necessary. This reality has been a motivation to a large number of publications, many of these using in vivo and, mainly, in vitro models.

The 8-methoxypsoralen (8-MOP), also called xanthotoxin, is a furanocoumarin (derivative of psoralen) that has been widely employed for many years, combined with irradiation with long- 
wavelength UV light (PUVA), to treat patients with vitiligo, and FDA also approved it for the treatment of cutaneous $T$ cell lymphoma (Cao et al., 2008). Photosensitizers and photodynamic therapy have been used in both pre-clinical and clinical studies for the treatment of brain tumors (Wilson and Patterson, 2008). However, there are descriptions of biological activity of some derivatives of psoralen even without UV irradiation (Rodighiero et al., 1996). Moreover, cytotoxic and antiproliferative effects have been attributed to pyrrolocoumarins and furanocoumarins, such as 8-MOP, and some of them were identified as potent topoisomerase I inhibitors (Kim et al., 2007; Diwan and Malpathak, 2009; Guiotto et al., 1995).

In this work, C6 cells, from rat glioma, as well as GL-15, a well characterized cell line from human glioblastoma (Bocchini et al., 1991), were used to evaluate the antiproliferative and apoptosisinducing potential of 8-MOP. The effects of 8-MOP were also studied on rat primary cultures of astrocytes to compare results. Additionally, three other cell lines, from different kinds of tumor, as well as several structurally related compounds were used to describe the whole potential of this new prototype of antitumor drug.

\section{Material and methods}

\subsection{Cell cultures}

Human glioblastoma GL-15 cells, rat glioma C6 cells, SCC3 (human lymphoma), CT-26 (murine colorectal cancer) and MDA-MB231 (human breast cancer) cell lines were cultured at $37{ }^{\circ} \mathrm{C}$ in DMEM, supplemented with $44 \mathrm{mM} \mathrm{NaHCO}, 10 \%$ fetal bovine serum, $100 \mathrm{IU} / \mathrm{mL}$ penicillin and $100 \mu \mathrm{g} / \mathrm{mL}$ streptomycin in a humidified atmosphere of $5 \% \mathrm{CO}_{2}$ and $95 \%$ air. Primary culture of astrocytes from Wistar rats were performed according to a previously described method (Pinheiro et al., 2006), and kept under same conditions. Culture medium for C6, GL-15 and astrocytes was also supplemented with $1 \mathrm{mM}$ pyruvic acid, $2 \mathrm{mM} \mathrm{L}(+)$-glutamine. The culture medium was changed every 2 days.

\subsection{Treatment with $8-M O P$}

The cells were seeded in Petri dishes of $35 \mathrm{~mm}$ in diameter or 96-well plates (according to the used test), at a density of $3.1 \times 10^{4}$ cells $/ \mathrm{cm}^{2}, 72 \mathrm{~h}$ prior to treatments, except for proliferation assays using Trypan blue dye and phase contrast microscopy analysis, in which the drug was added during the seeding of cells. The cultures were submitted to the treatment with $0.2,0.3$ or $0.4 \mathrm{mM} 8$-MOP or with $0.5 \%$ DMSO (vehicle) and incubated for 24 , 48 , or $72 \mathrm{~h}$ or $20 \mu \mathrm{M} 8$-MOP every two days for long-term (10 days) effect evaluation.

\subsection{Cell viability and proliferation analysis}

Cell viability was measured in 96 well plates by the classic MTT method. The MTT reagent dissolved in PBS was added to each well ( $1 \mathrm{mg} / \mathrm{mL}$ final concentration). Following additional 2-h incubation, $100 \mu \mathrm{L}$ of $20 \%$ SDS in dimethylformamide (DMF $50 \%$ in water, $\mathrm{pH}$ 4.7) was added to lyse cells. The absorbance was then measured at $540 \mathrm{~nm}$ using a microplate reader (THERMO PLATE, model TPreader - type B). 90\% Confluent and sub-confluent (50-60\%) cultures were tested. Total protein content in culture was admitted as cellularity indicator. To access it, cells were rinsed twice with PBS and dissolved in $0.5 \mathrm{~mL}$ of $1 \mathrm{M} \mathrm{NaOH}$ for $20 \mathrm{~min}$ at room temperature with gentle shaking. Proteins were relatively quantified by using a DC protein assay reagent kit (Bio-Rad, Hercules, CA, USA). Also, cell membrane integrity was evaluated by extracellular LDH levels measurement (see Supplementary methodology).
Furthermore, cell counting was used as a direct way to evaluate proliferation and it was carried out by trypan blue dye exclusion assay. In this case, after treatments, the culture medium was collected, and cells were removed from plates using 0.05\% trypsin, $20 \%$ EDTA in PBS for $5 \mathrm{~min}$. Cells were harvested and centrifuged at $168 \mathrm{~g}$ for $6 \mathrm{~min}$. Then, the pellet was suspended and mixed with fresh culture medium, and $0.05 \%$ trypan blue was added. Ten minutes after, the cells were counted in a hemocytometer. The percentages of inhibition of proliferation after the long-term exposure were calculated according to equation: $100\left(\Delta \mathrm{V}_{\mathrm{c}}-\left(\Delta \mathrm{V}_{\mathrm{t}}+\left(\mathrm{U}_{\mathrm{t}}-\mathrm{U}_{\mathrm{c}}\right)\right)\right.$ / $\Delta \mathrm{V}_{\mathrm{c}}$ ), in which $\Delta \mathrm{V}_{\mathrm{c}}=$ variation on number of viable control cells between first and tenth days; $\Delta V_{t}=$ variation on number of viable treated cells between first and tenth days; $U_{t}=$ unviable treated cells on the tenth day; $\mathrm{U}_{\mathrm{c}}=$ unviable control cells on the tenth day.

\subsection{Colony formation assay}

For the colony formation assay a basal layer of solid medium (0.2 $\mathrm{mL}$ of DMEM with $0.5 \%$ low melting point agarose) was deposited in each well. Therefore, an intermediate semi-solid $\left(0.2 \mathrm{~mL}\right.$ of DMEM with $0.35 \%$ low melting point agarose at $38{ }^{\circ} \mathrm{C}$ ) was deposited over this layer, in which the cells were dispersed (400/well). A third layer of liquid medium containing the drug (8MOP) or the vehicle $(0.001 \%$ DMSO) was deposited over the second one and was replaced every two days. After two weeks, the colonies were stained with $10 \%$ gentian violet for observation under an optical microscope. The number of colonies was counted in six wells for each group. The maximum diameter and its perpendicular axis for each colony were measured and the final diameter was the mean of these values. Ten random fields in each well were photographed for this procedure.

\subsection{Microscopy}

Cells were observed using an inverted phase contrast microscope (NIKON Eclipse TS100) to perform a qualitative analysis of cellularity and morphology. Ultra-structural analyses of both surface and cytoplasm of cells were also performed. For transmission electron microscopy, the cells were fixed in $4 \%$ paraformaldehyde and $2.5 \%$ glutaraldehyde (Polysciences) in $0.1 \mathrm{M}$ sodium cacodylate buffer, pH 7.4, postfixed in 1\% osmium tetroxide (Polysciences) and $0.08 \%$ potassium ferricyanide in the same buffer, dehydrated in acetone series, and embedded in Polybed resin (Polysciences). The sections were observed under a Zeiss EM109 transmission electron microscope (TEM). For scanning electron microscopy, the cells were cultured on poly- $l$-lysine treated coverslips and fixed as described above, dehydrated in ethanol series, dried by the critical point method in a Balzers apparatus, mounted on stubs, and covered with a 20 nm-thick gold layer. Cells were observed in a JSM 6390 LV Low Vacum - JEOL (EUA) scanning electron microscope (SEM). Fluorescence microscopy was also used (See Supplementary information).

\subsection{Migration assay}

Migratory capacity of the tumor cells was evaluated by Woundhealing assays. The cells were seeded and grown to $100 \%$ confluence Then, the cell layer was scratched in the middle of the wells using yellow tips, washed three times with PBS and the cells were grown further in serum-free medium at $37{ }^{\circ} \mathrm{C}$. The wounded monolayer of culture was recorded under inverted microscope at $0 \mathrm{~h}, 12 \mathrm{~h}, 30 \mathrm{~h}$, and $60 \mathrm{~h}$.

\subsection{Cell cycle and cell death analysis}

Flow cytometry analysis of DNA content was performed to 
assess the cell cycle phase distribution. After treatments, cells were harvested by trypsinization, fixed with cold ethanol, and stained with propidium iodide (PI). A fluorescence-activated flow cytometer (Becton-Dickinson, FranklinLakes, NJ, USA) was used for analysis. The software Cell Quest ${ }^{\mathrm{TM}} 3.1$ was used to generate histograms and determine the cell cycle phase distribution. Cell death was studied by using FITC-Annexin V and propidium iodide (PI) staining approach (annexin-V FITC-Kit, BioSource, Camarillo, U.S.A.), that identifies both apoptotic and necrotic cells, and apoptosis was confirmed by Hoescht staining of treated and control cultures (more details in Supplementary Methods).

\subsection{Analysis of proteins expression}

Expression of GFAP, and vimentin were investigated in astrocytes and brain tumor cells by western-blotting and immunocytochemistry. Vimentin expression in GL-15 cultures was also assessed by flow cytometry (more details in Supplementary Methods).

\subsection{Statistical analysis}

Data were showed as mean with SEM or median with range according to their distribution, analyzed by Shapiro-Wilk normality test and Skewness (normal: $<1$ or $>-1$ ) and Kurtosis (normal: $<2$ or $>-2$ ) calculation. Also according to the distribution, parametric or non-parametric statistic test were chosen, they are indicated in illustration legends. Experiments were performed at least in triplicate. Probability values of $\mathrm{p}<0.05$ were accepted as indication of statistically significant difference.

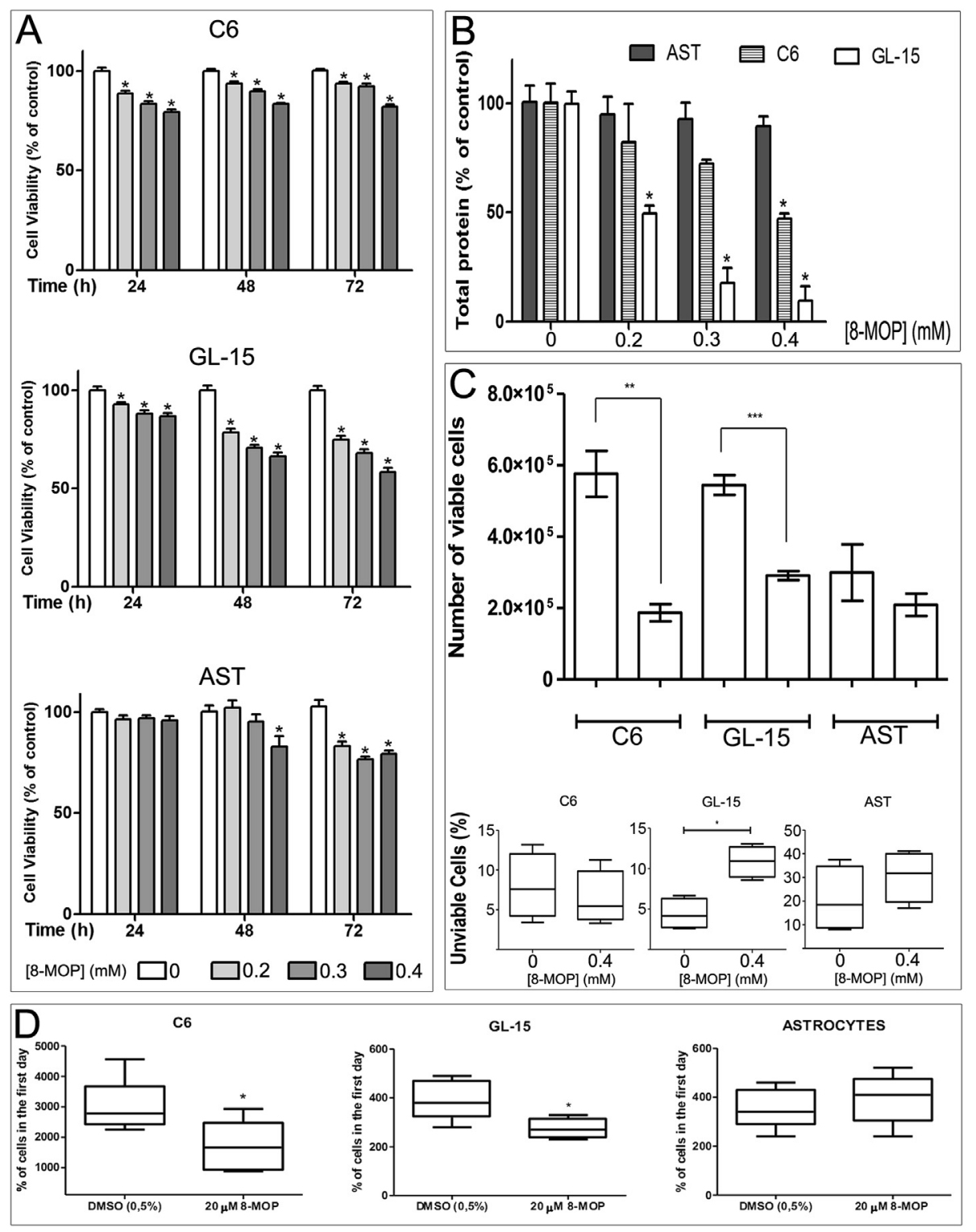

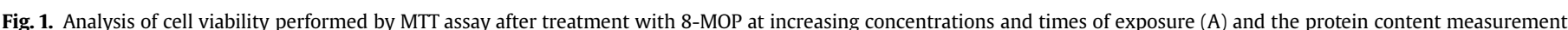

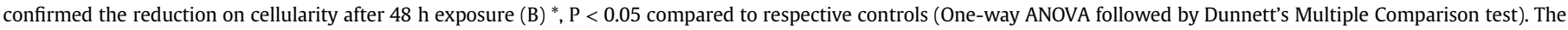

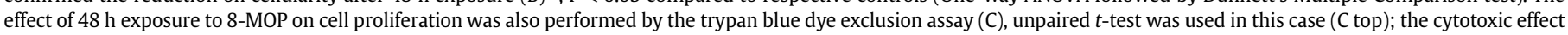

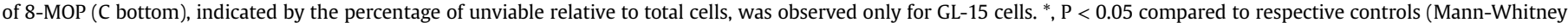

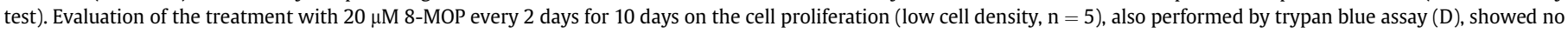
significant effect on astrocytes. However, the drug reduced proliferation of both glioma cell lines. *, P < 0.05 compared to respective controls (Mann-Whitney test). 


\section{Results}

3.1. 8-MOP reduced cell viability and cellularity more efficiently in tumor than in normal cells

MTT test showed a significant decrease in the viability of brain cells and indicated a selective action against other tumors. The crescent order of susceptibility to 8-MOP was astrocytes, C6 and GL-15 (Fig. 1A). 24 h exposition to $0.2 \mathrm{mM} 8$-MOP led to a decreased viability on GL-15 and C6 cells of $7.4 \pm 1.2 \%$ and $11.5 \pm 1.5 \%$, respectively, and the toxicity increased in a dose-dependent manner. Toxicity against astrocytes became evident only for treatment with $0.4 \mathrm{mM} 8$-MOP after $48 \mathrm{~h}$. A $72 \mathrm{~h}$ exposure promoted a maximum effect in GL-15 cells, but also decreased the cell viability of astrocytes. The total protein content measurement suggested that MTT results reflect reduction of cellularity (Fig. 1B). Trypan blue dye exclusion assay confirmed the reduction on cell growth after treatment (Fig. 1C). After 48 h, GL-15 cultures increased $172 \pm 14 \%$ in control conditions and $46 \pm 6 \%$ in the treated group. For C6 cultures, these values were $188 \pm 32 \%$ and "not apparent", respectively. In astrocytes, there was no significant effect. Cell death was not visually evident in all the experiments; it was confirmed by LDH assay (Supplementary Fig. 1). A mild cytotoxic effect of 8-MOP was observed only on GL-15 cells, which cannot explain the reduction on cellularity. The 10-days exposure to a low concentration of 8-MOP showed a cumulative effect only on tumor cells; an apparent toxicity was observed against C6 cells in this experiment, but it was not significant (Fig. 1D and Supplementary Table 1). Taken together, these results suggest that 8-MOP presents anti-proliferative action and is tumor cell selective.

\subsection{Antiproliferative effect of $8-\mathrm{MOP}$ is not related to cell cycle arrest}

Results from 8-MOP treatment on confluent (Fig. 2A) and subconfluent (Fig. 2B) cultures showed that the effect is more notable in Log-phase of the growth. Under sub-confluence, $\mathrm{C} 6$ cells (higher mitosis rate), were apparently more susceptible than GL15 cells. It was observed changes in tumor cells morphology and decrease on cellularity of sub-confluent cultures treated with 8MOP (Fig. 2 - pictures). The largest susceptibility of GL-15 cells to 8-MOP was visually evident. Astrocyte cultures were not affected. Furthermore, there was no astrocyte activation since treatment did not change GFAP expression (Fig. 2C). Despite the antiproliferative action, 8-MOP did not promote cell cycle arrest (Fig. 3A and Supplementary Fig. 2). In fact, there was no difference in number of colonies between vehicle and drug treated C6 cells, but 8-MOP slowed cell division, resulting in smaller colonies (Fig. 3B-F and Supplementary Fig. 3). GL-15 cells did not form colonies.
A
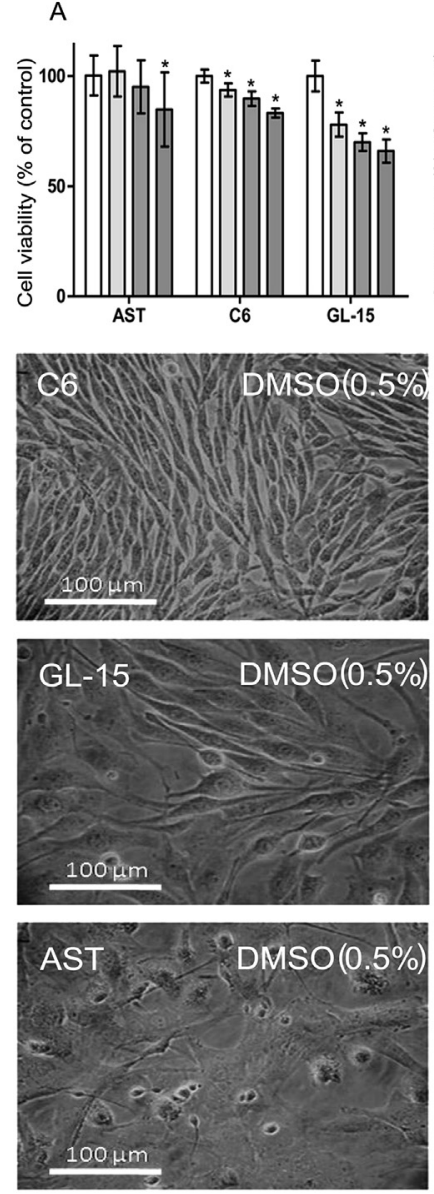

B
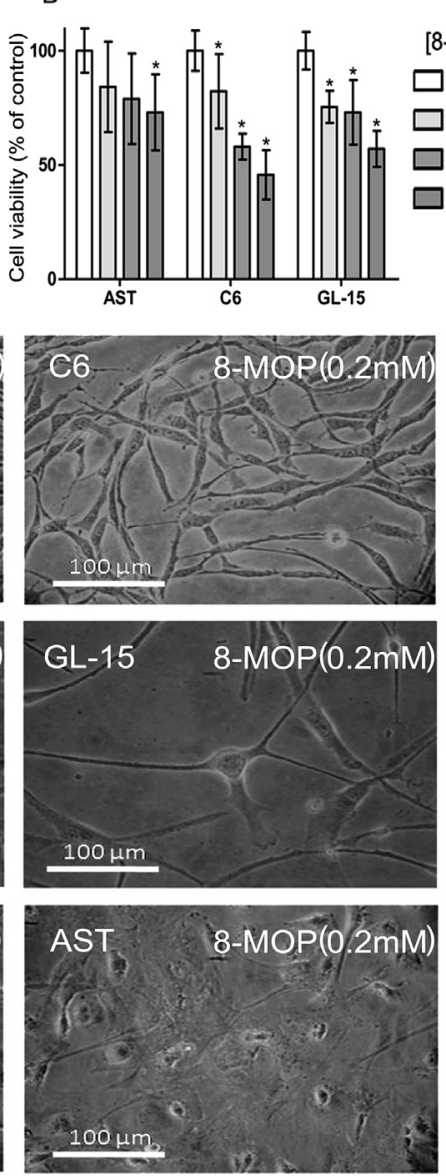
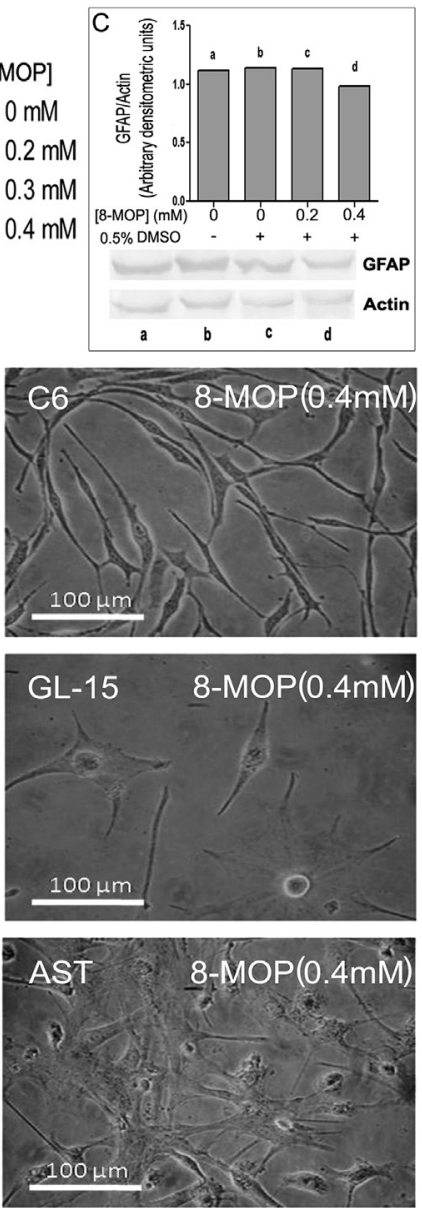

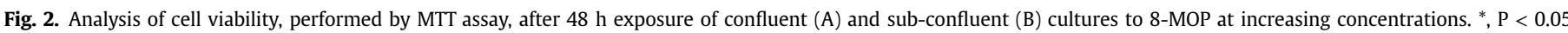

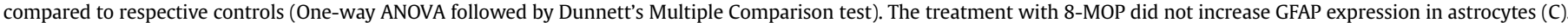

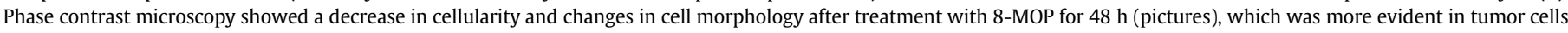
than in normal ones. 

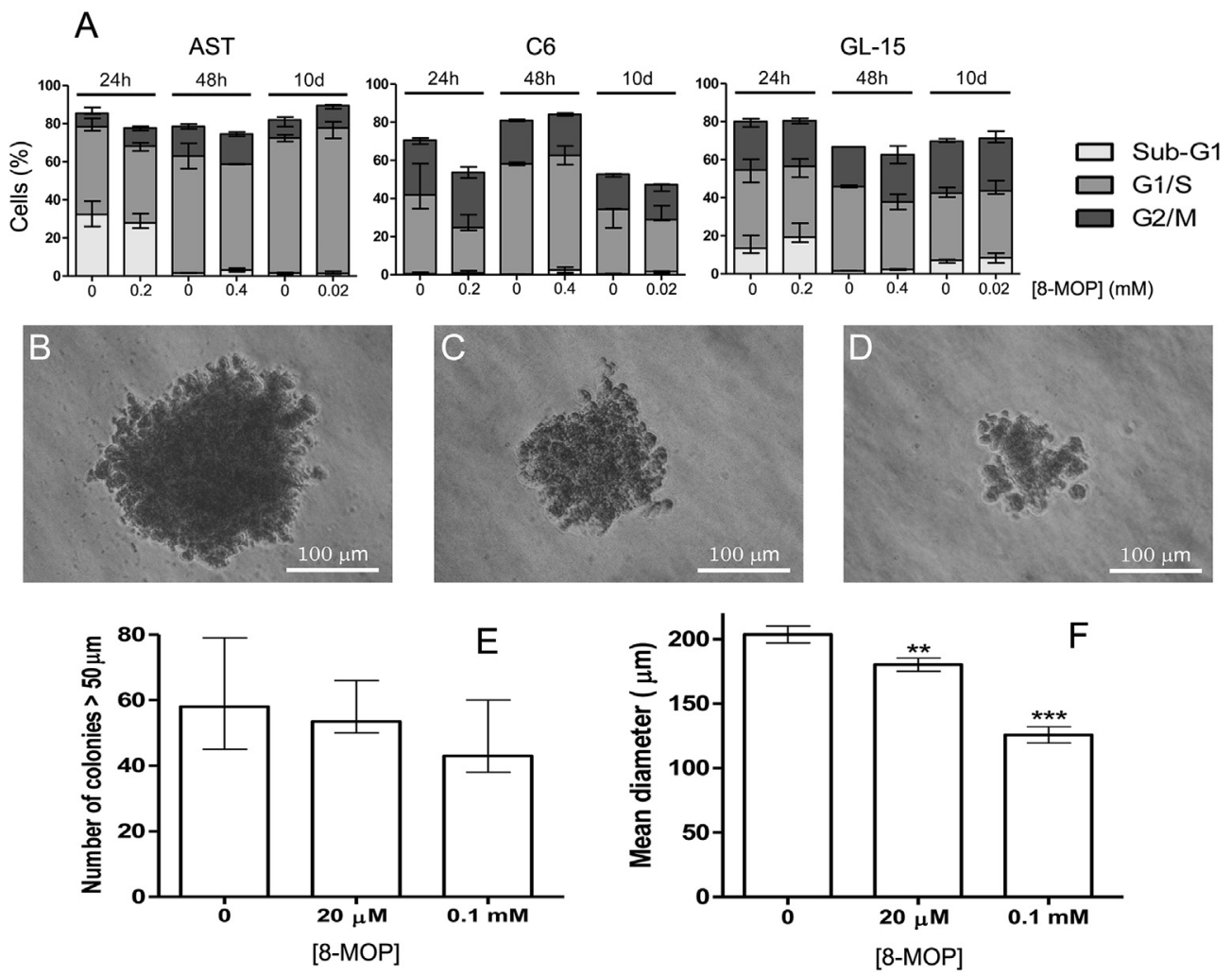

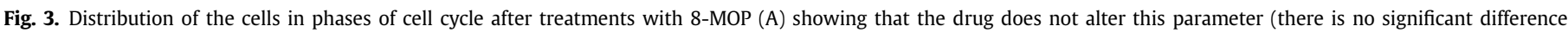

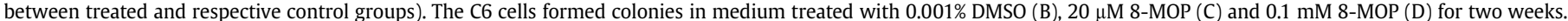

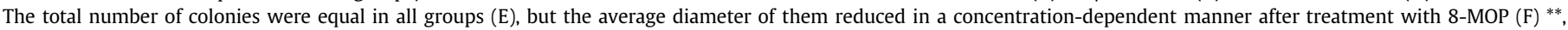
$\mathrm{P}<0.01$ and $^{* * *}, \mathrm{P}<0.001$ compared to respective controls (One-way ANOVA followed by Dunnett's Multiple Comparison test).

\subsection{8-MOP at high concentration induced cell death by apoptosis and changes in cell morphology}

Acute administration of 8-MOP at high concentration $(0.4 \mathrm{mM}$, $48 \mathrm{~h}$ ) was able to induce apoptosis in all kinds of cells (Supplementary Figs. 4 and 5). The amount of necrotic cells was not significant in all groups. The changes in cellular morphology visualized by phase contrast microscopy were confirmed by SEM in the tumor cells, but were not evident in astrocytes (Fig. 4A-F). Increasing of filopodia-like structures, often associated with migration, could be observed in the surface of tumor cells treated with 8-MOP (Fig. 4G), however, the migratory capacity of these cells was not affected (Fig. 4H). In fact, a mild inhibition of cell migration was observed in 8-MOP treated cells, but it was not significant (Supplementary Fig. 6). The drug was also able to change the pattern of vimentin expression in GL-15 cells (Supplementary Fig. 7), overexpression of this proteins seems to be related to morphological changes on these cells.

\subsection{Coumarin derivatives structurally related to 8-MOP presented different patterns of biological activity}

MTT assay after $48 \mathrm{~h}$ treatment of sub-confluent cultures was used as a screening technique to investigate the antitumor potential of coumarin derivatives structurally related to 8-MOP (Supplementary Fig. 8). In general, all compounds showed more significant activity in tumor cells than in normal ones (Fig. 5 and Supplementary Fig. 9). The coumarin core alone did not show activity, while the non-methoxylated psoralen was toxic for both tumor cells and astrocytes. If, however, the furan ring is removed from the structure, but the oxygen atom preserved, as in the structure of methoxyumbeliferone, the activity remains restricted to tumor cells. Moreover, the presence of nonpolar groups such as methyl or prenyl seems to potentiate the effect. The compound trimethylpsoralen showed selective antiproliferative activity at $0.6 \mu \mathrm{M}$ (Fig. 5). Besides decreased cell viability, some compounds also promoted changes in the morphology of tumor cells (Supplementary Fig. 10).

\subsection{Non glioma tumor cells respond differently to 8-MOP treatment}

8-MOP was tested on other cell lines (Supplementary Fig. 11). The treatment was not effective against colorectal CT-26 cells, but lymphoma SCC3 cells and breast cancer MDA-MB-231 cells had their viability affected. However, in these cases, high concentration of 8-MOP did not lead to different results in confluent and subconfluent cultures. Taken together these findings suggest that the drug has a specific pathway-dependent mechanism of action, otherwise the same pattern of response would be shown by all cells.

\section{Discussion}

In this work, a dose-dependent antiproliferative effect of 8-MOP was observed against glioma cells and normal rat astrocytes, but it was stronger in tumor cells. This effect was attested in the absence of UV light irradiation. The concentrations used in the tests are, apparently, very high to be considered for therapeutic purposes, but pharmacokinetic studies demonstrated that plasma concentrations of 8-MOP as high as $1 \mathrm{mM}$ can be achieved safely (Billard 

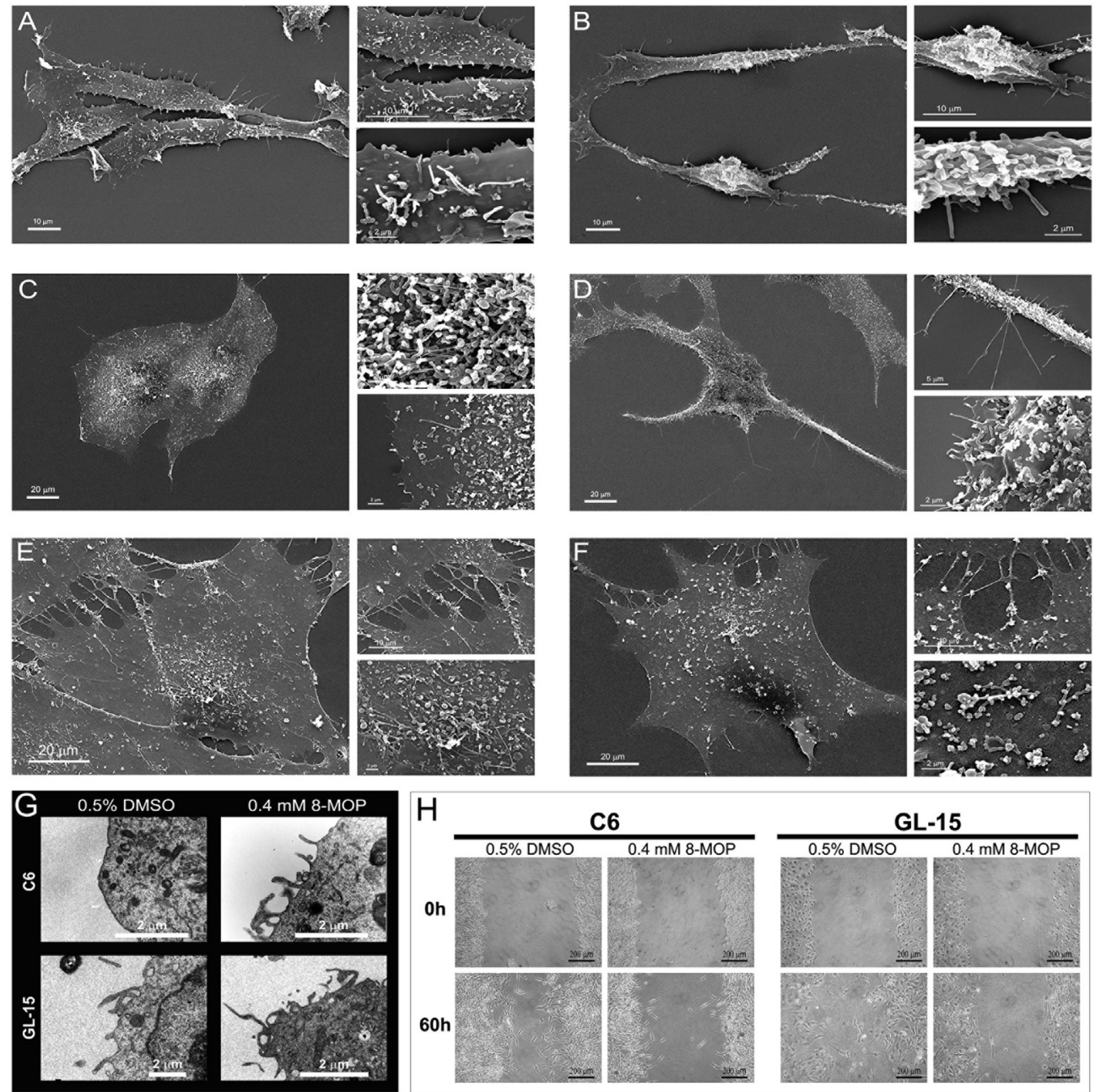

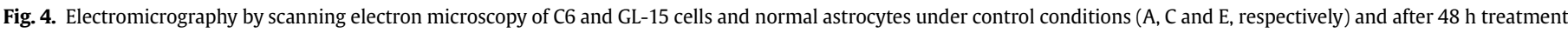

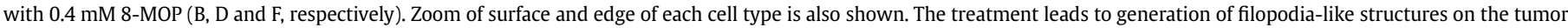
cells, also visible by transmission electronic microscopy $(G)$, but the 8-MOP did not increase cell migration $(H)$.

et al., 1995). This classical drug with an outstanding record of safety has real chance to be tested in clinical trials, in the near future, for the treatment of gliomas, which frequently do not respond to the main agent currently used in the therapy, temozolomide (TMZ) (Wang et al., 2015a; Beier et al., 2008). In fact, 1 mM TMZ after a 72$\mathrm{h}$ incubation promoted death in $24-81 \%$ (mean: $49.83 \%$ ) of glioma cells from six patients, when analyzed by the MTT assay (Pédeboscq et al., 2007). We found that a 72-h incubation with $0.4 \mathrm{mM} 8$-MOP promoted death on $41.68 \%$ of human glioblastoma GL-15 cells. Indeed, in our study $0.2 \mathrm{mM}$ 8-MOP was more effective against GL15 cells, which are extremely resistant to TMZ (de Oliveira et al., 2014), than $0.2 \mathrm{mM} \mathrm{TMZ}$ against GOS-3 and U-87 MG glioma cells (Patel et al., 2008).

The MTT test performed at sub-confluent conditions (log-phase of cell growth) indicated the antiproliferative action of 8-MOP, which was confirmed by additional tests. Cell death (apoptosis) was significant only at the higher concentration used. In fact, phase contrast microscopy, trypan blue staining, colony formation assay and LDH measurement did not show significant cell death after treatment with 8-MOP at 0.2 or $0.3 \mathrm{mM}$. A low dose-experiment was executed, but for a longer time exposure, simulating a real therapy. A chronic treatment with low concentrations could prevent toxic effects of an acute high dose administration. Data from this experiment showed antiproliferative effects against tumor cells even at low concentration, which indicates that a clinical therapeutic scheme with 8-MOP could be designed. Additionally, many neurological effects of 8-MOP suggest that this substance is able to cross the brain-blood barrier (Vernassière et al., 2006). Moreover, 8-MOP did not change GFAP expression in astrocytes. The presence of drugs can promote astrocyte activation, as identified by GFAP immunostaining (Goswami et al., 2015), which could interfere with tissue homeostasis and lead to various damages in normal cells.

Psoralens, like 8-MOP, have a hydrophobic nature and a planar aromatic structure, which enables them to intercalate between DNA base pairs, preferentially at 5'-TA-3' sites (Cao et al., 2008; Wu et al., 2009). The irradiation of psoralens with UVA (320-400 nm) leads to formation of monoadducts, diadducts and interstrand cross-links (ICL) (Rodighiero et al., 1996), that are believed to be the principal element in PUVA therapy. However, there are other mechanisms involved in the growth-inhibitory and apoptosisinducing effects of 5-methoxypsoralen (Lee et al., 2003). Intercalation itself results in a decrease in DNA helical twist and lengthening (Abassi Joozdani et al., 2015), which is the mechanism of action of some antitumor agents.

Despite clear impact of 8-MOP in proliferation, cell death was not observed at the conditions used for proliferation assays, in the other hand, the treatment did not promote cell cycle arrest. The 

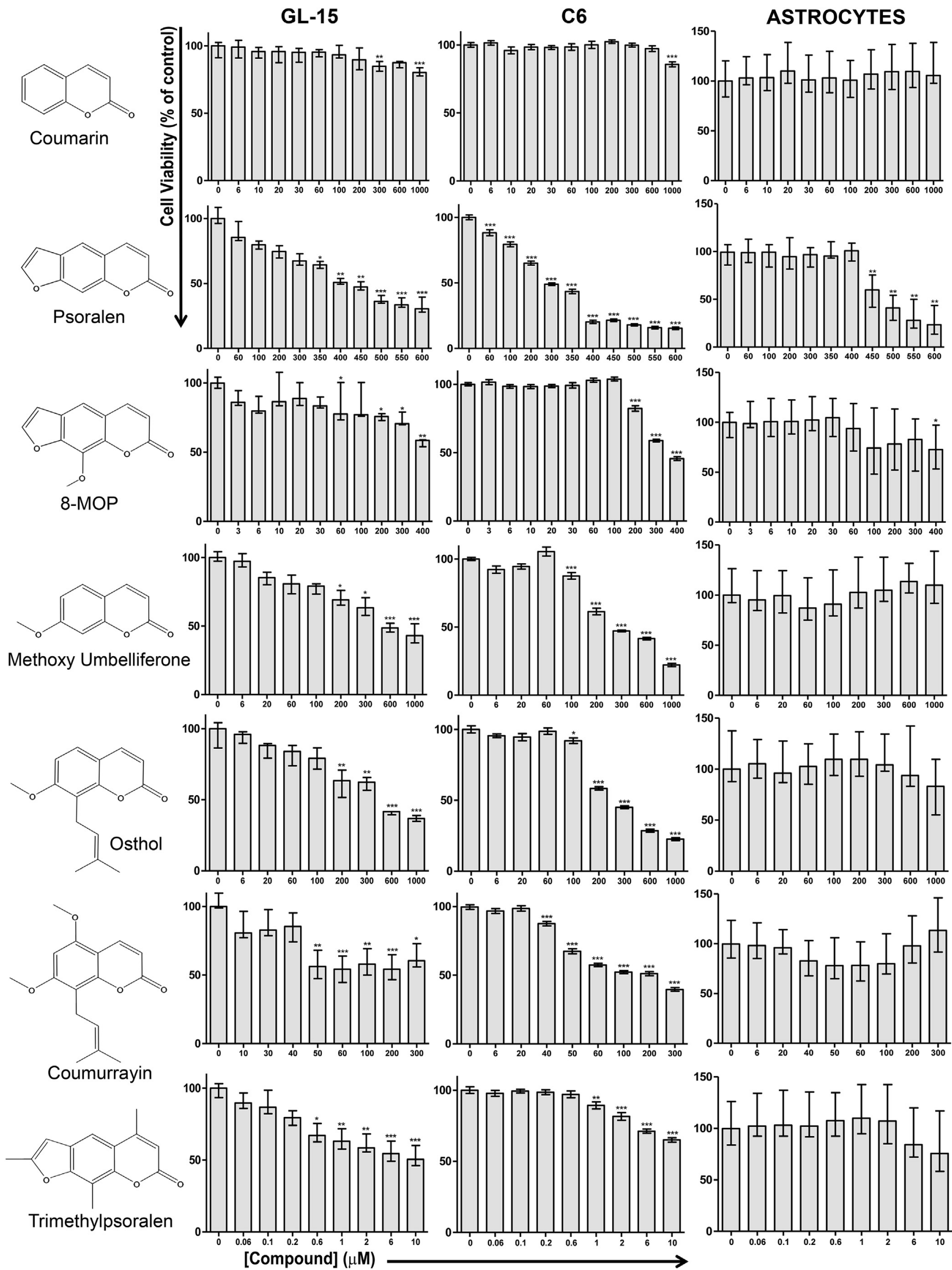

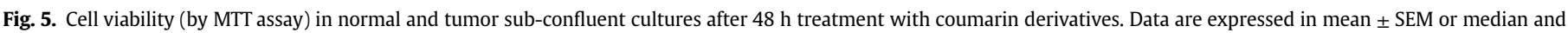

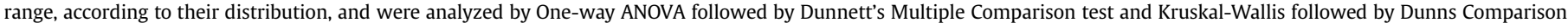
test, respectively. ${ }^{*}=\mathrm{p}<0.05 ;{ }^{* *}=\mathrm{p}<0.01 ;^{* * *}=\mathrm{p}<0.001$ compared to respective controls $(0.5 \%$ DMSO). 
most probable explanation for this apparent paradox is that the drug can slow down the cell division process by interfering with cell cycle controllers. In fact, it has been demonstrated that, after PUVA therapy, there are changes in cell cycle controlling proteins levels in the patients (Abou El-Ela et al., 2010). The detailed mechanism of action of 8-MOP remains under investigation, but if this hypothesis is confirmed it could prevent side effects common in many antitumor drugs (Terada et al., 2015). 8-MOP also promoted morphological changes in tumor cells. The induction of filopodia-like structures, for example, indicates possible pathways involving the actin cytoskeleton that could suffer modulation by drugs (Schäfer et al., 2010). These structures are often, but not necessarily, associated with the migration capability of cells (Arjonen et al., 2011), however, in this case 8-MOP did not increase cell migration. Vimentin expression increased in 8-MOP treated GL15 cells, mainly in cells with affected morphology. This effect is probably due to the antiproliferative action of 8 -MOP, since the reduction of cell density in the culture is itself a stimulus for vimentin expression, which also occurs after treatment with traditional chemotherapy (Trog et al., 2008). We have recently demonstrated that 8-MOP also inhibits the glutathione S-transferase $\pi$ (GSTP1) activity and increases cell susceptibility to apoptosis (de Oliveira et al., 2014), which could explain the proapoptotic action of 8-MOP at high concentrations.

Our data also pointed coumarin derivatives as a possible new class of antiproliferative agents and 8-MOP as a good prototype for future studies. The structure-activity relationship analysis pointed the oxygen atom in furan ring as mandatory for activity. All compounds tested have LogP values compatible with therapeutic applications, but the trimethylpsoralen (also clinically used) showed the best activity/concentration relationship, probably because of an increased availability. In fact, many classes of coumarin derivatives may be potential candidates for the treatment of cancer (Wang et al., 2015b; Liu et al., 2015). Novobiocin, for example, exhibited antitumor activity by binding to the molecular chaperone Hsp90 (Donnelly et al., 2008), and noscapine, which is not a coumarin derivative but has structural similarities to 8-MOP, was also able to inhibit the growth of glioma cells resistant to TMZ (Jhaveri et al., 2011).

In conclusion, the antiproliferative activity of 8-MOP in glioma cell lines, without UV light irradiation, demonstrated for the first time in this work, confirm that this substance is a good candidate as a new chemotherapeutic agent on glioma therapy, bringing new perspectives on the use of psoralen derivatives.

\section{Acknowledgments}

The authors acknowledge The National Council for Scientific and Technological Development of Brazil (CNPq) for support.

\section{Appendix A. Supplementary data}

Supplementary data related to this article can be found at http:// dx.doi.org/10.1016/j.neuint.2016.06.004

\section{References}

Abassi Joozdani, F., Yari, F., Abassi Joozdani, P., Nafisi, S., 2015. Interaction of sulforaphane with DNA and RNA. PLoS One 10, e0127541.

Abou El-Ela, M., Nagui, N., Mahgoub, D., El-Eishi, N., Fawzy, M., El-Tawdy, A., Abdel Hay, R., Rashed, L., 2010. Expression of cyclin D1 and p16 in psoriasis before and after phototherapy. Clin. Exp. Dermatol 35, 781-785.

Arjonen, A., Kaukonen, R., Ivaska, J., 2011. Filopodia and adhesion in cancer cell motility. Cell Adhes. Migr. 5, 421-430.

Beier, D., Röhrl, S., Pillai, D.R., Schwarz, S., Kunz-Schughart, L.A., Leukel, P., Proescholdt, M., Brawanski, A., Bogdhan, U., Trampe-Kieslich, A., Giebel, B.,
Wischhusen, J., Reifenberger, G., Hau, P., Beier, C.P., 2008. Temozolomide preferentially depletes cancer stem cells in glioblastoma. Cancer Res. 68, $5706-5715$.

Billard, V., Gambus, P.L., Barr, J., Minto, C.F., Corash, L., Tessman, J.W., Stickney, J.L. Shafer, S.L., 1995. The pharmacokinetics of 8-methoxypsoralen following i.v. administration in humans. Br. J. Clin. Pharmacol. 40, 347-360.

Bocchini, V., Casalone, R., Collini, P., Rebel, G., Lo Curto, F., 1991. Changes in glial fibrillary acidic protein and karyotype during culturing of two cell lines established from human glioblastoma multiforme. Cell Tissue Res. 265, 73-81.

Cao, H., Hearst, J.E., Corash, L., Wang, Y., 2008. LC-MS/MS for the detection of DNA interstrand cross-links formed by 8-methoxypsoralen and UVA irradiation in human cells. Anal. Chem. 80, 2932-2938.

de Oliveira, D.M., de Farias, M.T., Teles, A.L., Dos Santos Junior, M.C., de Cerqueira, M.D., Lima, R.M., El-Bachá, R.S., 2014. 8-Methoxypsoralen is a competitive inhibitor of glutathione S-transferase P1-1. Front. Cell Neurosci. 8, 308.

de Oliveira, M.S., Cechim, G., Braganhol, E., Santos, D.G., Meurer, L., Castro, C.G.J., Brunetto, A.L., Schwarstmann, G., Battastini, A.M., Lenz, G., Roesler, R., 2009. Anti-proliferative effect of the gastrin-release peptide receptor antagonist RC3095 plus temozolomide in experimental glioblastoma models. J. Neurooncol. 93, 191-201.

Diwan, R., Malpathak, N., 2009. Furanocoumarins: novel topoisomerase I inhibitors from Ruta graveolens L. Bioorg. Med. Chem. 17, 7052-7055.

Donnelly, A.C., Mays, J.R., Burlison, J.A., Nelson, J.T., Vielhauer, G., Holzbeierlein, J., Blagg, B.S., 2008. The design, synthesis, and evaluation of coumarin ring derivatives of the novobiocin scaffold that exhibit antiproliferative activity. J. Org. Chem. 73, 8901-8920.

Garrido, W., Rocha, J.D., Jaramillo, C., Fernandez, K., Oyarzun, C., San Martin, R., Quezada, C., 2014. Chemoresistance in high-grade gliomas: relevance of adenosine signalling in stem-like cells of glioblastoma multiforme. Curr. Drug Targets 15, 931-942.

Goswami, P., Gupta, S., Joshi, N., Sharma, S., Singh, S., 2015. Astrocyte activation and neurotoxicity: a study in different rat brain regions and in rat C6 astroglial cells. Environ. Toxicol. Pharmacol. 40, 122-139.

Guiotto, A., Chilin, A., Manzini, P., Dall'Acqua, F., Bordin, F., Rodighiero, P., 1995. Synthesis and antiproliferative activity of furocoumarin isosters. Farmaco 50, 479-488.

Jhaveri, N., Cho, H., Torres, S., Wang, W., Schönthal, A.H., Petasis, N.A., Louie, S.G., Hofman, F.M., Chen, T.C., 2011. Noscapine inhibits tumor growth in TMZresistant gliomas. Cancer Lett. 312, 245-252.

Kim, Y.K., Kim, Y.S., Ryu, S.Y., 2007. Antiproliferative effect of furanocoumarins from the root of Angelica dahurica on cultured human tumor cell lines. Phytother. Res. 21, 288-290.

Lee, Y.M., Wu, T.H., Chen, S.F., Chung, J.G., 2003. Effect of 5-methoxypsoralen (5$\mathrm{MOP}$ ) on cell apoptosis and cell cycle in human hepatocellular carcinoma cell line. Toxicol. In Vitro 17, 279-287.

Liu, H., Wang, Y., Sharma, A., Mao, R., Jiang, N., Dun, B., She, J.X., 2015. Derivatives containing both coumarin and benzimidazole potently induce caspasedependent apoptosis of cancer cells through inhibition of PI3K-AKT-mTOR signaling. Anticancer Drugs 26, 667-677.

Omuro, A., DeAngelis, L.M., 2013. Glioblastoma and other malignant gliomas: a clinical review. JAMA 310, 1842-1850.

Patel, R., Shervington, L., Lea, R., Shervington, A., 2008. Epigenetic silence of telomerase and a non-alkylating agent as a novel therapeutic approach for glioma. Brain Res. 1188, 173-181.

Pédeboscq, S., L’Azou, B., Liguoro, D., Pometan, J.P., Cambar, J., 2007. Interindividual differences in anticancer drug cytotoxicity in primary human glioblastoma cells Exp. Toxicol. Pathol. 58, 247-253.

Pinheiro, A.M., Costa, S.L., Freire, S.M., Almeida, M.A., Tardy, M., El Bachá, R. Costa, M.F., 2006. Astroglial cells in primary culture: a valid model to study Neospora caninum infection in the CNS. Vet. Immunol. Immunopathol. 113, $243-247$.

Rodighiero, P., Guiotto, A., Chilin, A., Bordin, F., Baccichetti, F., Carlassare, F. Vedaldi, D., Caffieri, S., Pozzan, A., Dall'Acqua, F., 1996. Angular furoquinolinones, psoralen analogs: novel antiproliferative agents for skin diseases. Synthesis, biological activity, mechanism of action, and computer-aided studies. J. Med. Chem. 39, 1293-1302.

Schäfer, C., Born, S., Möhl, C., Houben, S., Kirchgessner, N., Merkel, R., Hoffmann, B., 2010. The key feature for early migratory processes: dependence of adhesion, actin bundles, force generation and transmission on filopodia. Cell Adhes. Migr. 4, 215-225.

Terada, T., Noda, S., Inui, K., 2015. Management of dose variability and side effects for individualized cancer pharmacotherapy with tyrosine kinase inhibitors. Pharmacol. Ther. 152, 125-134.

Trog, D., Yeghiazaryan, K., Schild, H.H., Golubnitschaja, O., 2008. Up-regulation of vimentin expression in low-density malignant glioma cells as immediate and late effects under irradiation and temozolomide treatment. Amino Acids 34, 539-545.

Vernassière, C., Petitpain, N., Martin, S., Tréchot, P., Barbaud, A., Schmutz, J.L., 2006. 8-Methoxypsoralen and neurological disorders: from dysosmia to migraine. Photodermatol. Photoimmunol. Photomed. 22, 217-218.

Wang, J., Lu, M.L., Dai, H.L., Zhang, S.P., Wang, H.X., Wei, N., 2015b. Esculetin, a coumarin derivative, exerts in vitro and in vivo antiproliferative activity against 
hepatocellular carcinoma by initiating a mitochondrial-dependent apoptosis pathway. Braz. J. Med. Biol. Res. 48, 245-253.

Wang, X., Jia, L., Jin, X., Liu, Q., Cao, W., Gao, X., Yang, M., Sun, B., 2015a. NF-кB inhibitor reverses temozolomide resistance in human glioma TR/U251 cells. Oncol. Lett. 9, 2586-2590.
Wilson, B.C., Patterson, M.S., 2008. The physics, biophysics and technology of photodynamic therapy. Phys. Med. Biol. 53, R61-R109.

Wu, J.H., Wilson, J.B., Wolfreys, A.M., Scott, A., Jones, N.J., 2009. Optimization of the comet assay for the sensitive detection of PUVA-induced DNA interstrand crosslinks. Mutagenesis 24, 173-181. 